\title{
Vitamin D and cancer mortality in elderly women
}

\author{
Germaine Wong ${ }^{1,2,3^{*}}$, Wai Hon Lim ${ }^{4,5}$, Joshua Lewis ${ }^{4,6}$, Jonathan C Craig ${ }^{1,2}$, Robin Turner ${ }^{2}$, Kathy Zhu ${ }^{4,6}$, \\ Ee Mun $\operatorname{Lim}^{7}$ and Richard Prince ${ }^{4,6}$
}

\begin{abstract}
Background: There is increasing evidence that vitamin D deficiency is a risk factor for cancer, however it remains uncertain whether vitamin $D$ deficiency also predisposes to death from cancer. The aim of the study was to determine the association between serum 25-hydroxy-vitamin D $(25(\mathrm{OH}) \mathrm{D})$ concentrations and cancer-specific mortality in a community-based cohort of older post-menopausal women.

Methods: Cox proportional regression analyses were conducted to examine the association between serum 25 $(\mathrm{OH}) \mathrm{D}$ concentrations and the risk of overall and site-specific cancer mortality in a cohort of elderly women.

Results: Over a median follow-up time of 10 years, a total of 84 cancer deaths were observed. Women with lower serum $25(\mathrm{OH}) \mathrm{D}$ concentrations were at an increased risk of cancer death, but not for incident cancer. The excess risk for cancer death was observed with serum $25(\mathrm{OH}) \mathrm{D}$ concentration less than $64 \mathrm{nmol} / \mathrm{L}$ (the median value) [adjusted HR: 1.61 (95\% Cl: $1.02-2.54, p=0.04$ ]. For every $30 \mathrm{nmol} / \mathrm{L}$ reduction in serum $25(\mathrm{OH}) \mathrm{D}$ concentrations, there was a 30\% increase in the overall risk of cancer death [adjusted HR: 1.33; 95\% Cl: $1.03-1.72, p=0.02$ ]. The excess risk appeared to be site-specific and greatest in those with haematological cancers [adjusted HR: 2.13: 95\% Cl: $1.0-4.55, p=0.05]$.
\end{abstract}

Conclusions: In elderly women, lower serum $25(\mathrm{OH})$ D concentrations appear to be an independent risk factor for cancer-specific mortality, but not a risk factor for the development of cancer.

Keywords: Vitamin D, Cancer mortality, Survival analyses

\section{Background}

Vitamin D deficiency is increasingly recognised as an important global public health problem. There is a growing body of epidemiological evidence demonstrating an inverse relationship between lower serum 25-hydroxyvitamin D $(25(\mathrm{OH}) \mathrm{D})$ concentrations and adverse health outcomes in the general population [1,2]. Among postmenopausal women with serum $25(\mathrm{OH})$ D concentrations less than $40 \mathrm{nmol} / \mathrm{L}$, there was at least a two-fold increased risk of all-cause and cardiovascular-related mortality compared to women with $25(\mathrm{OH}) \mathrm{D}$ concentrations greater than $64 \mathrm{nmol} / \mathrm{L}[3,4]$. Observational studies have shown that lower serum levels of $25(\mathrm{OH})$ D concentrations may also be linked to several types of common cancers such as breast, prostate, colorectal and skin [3,5-9].

\footnotetext{
* Correspondence: germaine.wong@health.nsw.gov.au

${ }^{1}$ Centre for Kidney Research, Children's Hospital at Westmead, Westmead, Australia

${ }^{2}$ School of Public Health, Sydney Medical School, The University of Sydney, Sydney, Australia

Full list of author information is available at the end of the article
}

Two controlled trials have assessed the impact of vitamin D supplementation and the incidence of cancer with conflicting results. The largest trial involved over 36,000 women randomized to combination calcium and vitamin D supplementation and matching placebo and found no significant effects on the incidence of cancer in postmenopausal women after an average of 7 years of follow up [10]. The other randomized controlled trial found a significant reduction in overall cancer risk by $60 \%$ with calcium and vitamin D supplementation in 1,179 healthy post-menopausal women with high baseline serum 25 $(\mathrm{OH}) \mathrm{D}$ concentrations over a follow-up period of 4 years [11].

Observational studies have also produced conflicting results regarding the risk of cancer death and reduced serum $25(\mathrm{OH})$ D concentrations. Several population-based cohort studies have shown a linear association between lower serum $25(\mathrm{OH})$ D concentrations and an increased risk of overall cancer mortality [12-15], whilst another study reported no increased risk of cancer death associated with vitamin D 
deficiency [16]. Recently, a meta-analysis of prospective cohort studies demonstrated a strong, inverse and independent relationship between serum $25(\mathrm{OH}) \mathrm{D}$ concentrations and non-vascular mortality. After adjustment for measured confounders, cause-specific analyses showed that there was a $16 \%$ reduction in cancer mortality for every 2 -fold increase in baseline serum $25(\mathrm{OH}) \mathrm{D}$ concentrations [17]. However, a more recent systematic review of prospective epidemiological studies has failed to demonstrate a consistent association between $25(\mathrm{OH})$ D concentration and cancer mortality in the general population [18]. Previous studies, however, have not examined the threshold of serum 25 $(\mathrm{OH}) \mathrm{D}$ concentrations that is associated with an increased in site-specific cancer deaths in older women, nor taken into consideration the competing risk of death when examining cancer-specific mortality. In this study, we aimed to determine the association between serum 25 $(\mathrm{OH}) \mathrm{D}$ concentrations and cancer-specific mortality in a community-based cohort of older women.

\section{Methods}

\section{Study population}

Data were obtained from a cohort of elderly women recruited to a randomised controlled trial of oral calcium supplements to prevent osteoporotic fractures, the Calcium Intake Fracture Outcome Study (CAIFOS) Australian Clinical Trials Registry Registration Number: ACTRN012607000055404). Human ethics approval for the use of linked data for the project was provided by the Western Australian Department of Health Human Research Ethics Committee (DOHWA HREC), project number \#2009/24. Full details of the recruitment methods are reported elsewhere [19]. In short, a total of 1500 women were recruited in 1998 and randomised to receive either $1.2 \mathrm{~g}$ of elemental calcium in the form of calcium carbonate or a matching placebo. Participants were followed over 10 years.

Baseline data were collected on self-reported medical and treatment histories, and the associated major risk factors such as smoking status and history of alcohol intake. Systolic and diastolic blood pressures were recorded using a mercury column manometer with an adult cuff after the participants had been seated and resting for at least 5 minutes. Baseline weight (using digital scales with participants wearing light clothes and no shoes), height (assessed using a stadiometer) and blood pressure (an average of 3 measurements) were obtained at recruitment. Blood samples were also taken for creatinine, albumin, calcium, phosphate, total cholesterol and triglyceride. Prevalent chronic kidney disease was identified using hospital records between 1980 and 1998.

\section{Assessment of exposure}

Serum $25(\mathrm{OH})$ D2 and D3 concentrations were determined using a validated LC-MS/MS (Liquid Chromatography
Tandem Mass Spectrometry) method at the RDDT Laboratories (Bundoora, VIC, Australia). Between-run coefficients of variation (CVs) were $10.1 \%$ at a 25 $(\mathrm{OH}) \mathrm{D} 2$ mean concentration of $12 \mathrm{nmol} / \mathrm{L}$ and $11.3 \%$ at a $25(\mathrm{OH}) \mathrm{D} 3$ mean concentration of $60 \mathrm{nmol} / \mathrm{L}$. Our exposure factor, serum $25(\mathrm{OH}) \mathrm{D}$ concentration, is the combined serum $25(\mathrm{OH}) \mathrm{D} 2$ and D3 concentrations.

\section{Western Australia data linkage system}

The Western Australia Data Linkage System (WADLS) is a comprehensive, population-based linkage system connecting 40 years of data from over thirty health related datasets for Western Australian residents coded using International Classification of Diseases (ICD) codes. The linkage system provides a complete validated record of every participant's primary diagnosis hospitalizations and up to twenty-one additional diagnosis hospitalizations codes and cause of death from the coded records of the death certificates or from cancer registry.

\section{Record linkage}

The Human Ethics Committee of the University of Western Australia approved the study and written informed consent was obtained prior to recruitment. The linkage process, using probabilistic linkage software, was carried out at Data Linkage Western Australia. Using key identifiers such as age, gender, addresses, post-codes from the CAIFOS study cohort, the WADLS then created a unique data linkage key to records of the same person within the WADLS database and the process would take multiple passes through datasets using different arrangements of the data items at each pass.

\section{Assessments of deaths}

Cancer and non-cancer deaths were provided by the WADLS as documented on the hospital death certificates and previous medical history, and the coded discharge diagnosis data including all public and private inpatient hospitalizations and deaths within Western Australia using the ICD $9^{\text {th }}$ and $10^{\text {th }}$ and the revision codes for malignancy (ICD-10-AM codes C15-26, C3039, C43-58, C64-75), atherosclerotic vascular disease: ischemic heart disease excluding arrhythmias (ICD-9-CM codes 410-414 and ICD-10-AM codes I20-I25); heart failure (ICD-9-CM code 428 and ICD-10-AM code I50); cerebrovascular disease excluding hemorrhage (ICD-9CM codes 433-438 and ICD-10-AM codes I63-69, G45.9) and peripheral arterial disease (ICD-9-CM codes 440-444 and ICD-10-AM codes I70-74).

\section{Statistical analyses}

Statistical analyses were performed using Stata 11 (Stata Crop, 4905 Lakeway Drive College Station, Texas 77845, USA) and SAS 9.3 (SAS Institute Inc, 100 SAS Campus 
Drive Cary, NC 27513-2414, USA). Baseline characteristics of women with the different baseline serum $25(\mathrm{OH})$ $\mathrm{D}$ concentrations were compared using student's $t$ test for means and chi-square for proportions (Table 1). The follow-up periods in survival analyses were defined from the time of first inclusion into the trial (from 1998 through 2008) to the time of death from cancer. People alive or died from other causes were censored at the end of the follow-up period ( $31^{\text {st }}$ December 2008) or date of death.

\section{Cause-specific analyses for cancer death}

The proportion of participants alive was calculated using the Kaplan-Meier method. Univariate Cox regression models were developed to assess the risk factors of cancer mortality within the cohort. All explanatory variables that had an association with cancer death at $\mathrm{P}<0.25$ in the unadjusted analyses were included in the multivariable-adjusted analyses. Using a step-wise backward elimination process, the least significant variables were then removed from the base model. Only variables with $\mathrm{P}<0.05$ remained in the final parsimonious model. In all models, we adjusted for age, season, and smoking status. Potential effect modification was also tested between the study factor (serum $25(\mathrm{OH}) \mathrm{D}$ concentrations) and all other covariates using the two-way interaction term. There were no effect modifications between serum $25(\mathrm{OH})$ D concentration and other study factors. The proportional hazard assumptions of all Cox regression models were tested statistically and graphically by plotting the Schoenfield residuals. Site specific analyses were also performed to assess the relationship between reduced serum $25(\mathrm{OH}) \mathrm{D}$ concentrations and the risk of the six most

Table 1 Baseline characteristics of participants $(n=1188)$

\begin{tabular}{|c|c|c|c|}
\hline & \multicolumn{2}{|c|}{ 25-hydroxy-vitamin D concentration ( $\mathrm{nmol} / \mathrm{L}$ ) } & \multirow{2}{*}{$\begin{array}{l}P \text { values for } \\
\text { differences }\end{array}$} \\
\hline & $\begin{array}{l}\text { Above median }(\geq 64) \\
(n=597)\end{array}$ & $\begin{array}{l}\text { Below median }(<64) \\
(\mathrm{n}=591)\end{array}$ & \\
\hline \multicolumn{4}{|l|}{ Patient characteristics } \\
\hline Age at entry (years, mean, sd) & $75.1(2.7)$ & $75.2(2.7)$ & 0.54 \\
\hline Body mass index $\left(\mathrm{kg} / \mathrm{m}^{2}\right.$, mean, $\left.\mathrm{sd}\right)$ & $26.8(4.5)$ & $27.4(4.9)$ & 0.02 \\
\hline Systolic blood pressure (mmHg, mean, sd) & $138.0(18.1)$ & $137.4(17.9)$ & 0.57 \\
\hline Diastolic blood pressure (mmHg, mean, sd) & $73.4(11.0)$ & $72.3(10.7)$ & 0.07 \\
\hline Previous and current smokers (n, \%) & $219(35.1)$ & $231(37.3)$ & 0.49 \\
\hline Diabetes (n, \%) & $36(6.0)$ & $46(7.8)$ & 0.24 \\
\hline Chronic kidney disease (n, \%) & $43(6.9)$ & $41(6.6)$ & 0.83 \\
\hline Cardiovascular disease $(n, \%)$ & $104(16.7)$ & $90(14.5)$ & 0.29 \\
\hline Daily alcohol use (grams, mean, sd) & $6.1(9.0)$ & $6.4(9.6)$ & 0.62 \\
\hline \multicolumn{4}{|l|}{ Medication use (n, \%) } \\
\hline $\begin{array}{l}\text { Angiotension-converting enzyme inhibitors or } \\
\text { angiotensin II receptor blockers }\end{array}$ & $91(14.6)$ & $83(13.4)$ & 0.54 \\
\hline Beta-blockers & $81(13.0)$ & $68(11.0)$ & 0.27 \\
\hline Diuretics & 79 (12.7) & $96(15.5)$ & 0.16 \\
\hline Treatment with calcium supplements ( $\mathrm{n}, \%$ ) & $314(50.4)$ & $332(53.6)$ & 0.27 \\
\hline \multicolumn{4}{|l|}{ Seasons at enrolment (n, \%) } \\
\hline Summer & $7(1.1)$ & $19(3.1)$ & $<0.001$ \\
\hline Spring & $227(36.4)$ & $311(50.2)$ & \\
\hline Autumn & $192(30.8)$ & $213(34.4)$ & \\
\hline Winter & $197(31.6)$ & $77(12.4)$ & \\
\hline \multicolumn{4}{|l|}{ Laboratory measurements } \\
\hline Creatinine (umol/L, mean, sd) & $79.8(15.9)$ & $76.1(14.9)$ & $<0.001$ \\
\hline Albumin (g/L, mean, sd) & $44.0(2.7)$ & $43.6(3.2)$ & 0.004 \\
\hline Calcium (mmol/L, mean, sd) & $2.35(0.1)$ & $2.32(0.1)$ & 0.005 \\
\hline Phosphate (mmol/L, mean, sd) & $1.18(0.1)$ & $1.17(0.1)$ & 0.61 \\
\hline Estradiol & $26.7(14.6)$ & $27.9(17.8)$ & 0.27 \\
\hline Estimated GFR (ml/min/1.73 $\mathrm{m}^{2}$, mean, sd) & $64.9(13.3)$ & $68.3(13.2)$ & $<0.001$ \\
\hline
\end{tabular}


common cancer deaths within the cohort of elderly women. The serum $25(\mathrm{OH}) \mathrm{D}$ concentrations were modelled as a continuous and categorical variable (less than and greater or equal than the median serum $25(\mathrm{OH}) \mathrm{D}$ concentrations $[<64 \mathrm{nmol} / \mathrm{L}$ or $\geq 64 \mathrm{nmol} / \mathrm{L}])$. We also used fractional polynomials in the Cox regression model to evaluate the functional form of the association between the continuous variable of serum $25(\mathrm{OH})$ D concentrations and overall cancer mortality. The hazard ratio for the difference between the serum $25(\mathrm{OH}) \mathrm{D}$ concentrations and the median value of $64 \mathrm{nmol} / \mathrm{L}$ was estimated from the model coefficient and plotted to show the change in the risk of cancer death with lower and higher serum $25(\mathrm{OH})$ D concentrations from the median value.

\section{Cause-specific analyses for cancer incidence}

To determine whether the higher risk of cancer mortality was a reflection of the underlying cancer risk among those with reduced serum $25(\mathrm{OH})$ D concentrations, we also assessed the association between overall cancer incidence and serum $25(\mathrm{OH}) \mathrm{D}$ concentrations in the adjusted Cox regression model.

\section{Competing risk analyses}

As a secondary analysis, we conducted a nonparametric estimation of the cumulative incidence of cancer mortality in participants with varying baseline serum $25(\mathrm{OH})$ $\mathrm{D}$ concentrations, taking into account the informative nature of censoring due to competing risk. The cumulative incidence of cancer death is estimated using two main steps. We first considered the event of interests (i.e. cancer death) and other competing events such as vascular death as "events" and then calculated the KaplanMeier estimate of the overall "events". Anyone who was not experiencing the "event" (i.e. event free) was considered censored [20].

\section{Sensitivity analyses}

To ensure that all cancer diagnoses and subsequent deaths occurred before measurements of serum $25(\mathrm{OH})$ D concentrations were taken, we had excluded participants who died from cancer within the first two years since the inception of the study in our sensitivity analyses. We also assessed the risk of cancer mortality among those with lower serum concentrations of 25 $(\mathrm{OH}) \mathrm{D}$ (less than $46 \mathrm{nmol} / \mathrm{L}$ ) compared to those with the highest quartile of serum $25(\mathrm{OH}) \mathrm{D}$ concentrations $(\geq 83 \mathrm{nmol} / \mathrm{L})$.

\section{Results}

From a total of 1500 participants, 228 (15.2\%) with incomplete serum $25(\mathrm{OH}) \mathrm{D}$ concentration and a further 84 participants (5.6\%) with cancers diagnosed prior to inception of the study were excluded, leaving a total of
1188 participants in the final analyses. The median age, body mass index (BMI), and baseline serum $25(\mathrm{OH}) \mathrm{D}$ concentrations of those included in the study were 75.1 (Interquartile range (IQR): 73 to 77 ) years, 26.5 (IQR: 23.8 to 29.7 ) $\mathrm{kg} / \mathrm{m}^{2}$ and 64 (IQR: 46.2 to 83.2 ) $\mathrm{nmol} / \mathrm{L}$, respectively. The median follow-up period was 10 years (interquartile range: 0.41 years), resulting in 12,647 persons-years of follow-up.

\section{Baseline characteristics of the study participants}

The baseline characteristics are shown in Table 1. A total of 591 (49.7\%) participants had serum $25(\mathrm{OH}) \mathrm{D}$ concentrations less than $64 \mathrm{nmol} / \mathrm{L}$. Compared to those with serum $25(\mathrm{OH}) \mathrm{D}$ concentrations above or equal to the median $(\geq 64 \mathrm{nmol} / \mathrm{L})$, participants with serum $25(\mathrm{OH}) \mathrm{D}$ concentrations less than $64 \mathrm{nmol} / \mathrm{L}$ had lower BMI $(\mathrm{p}=0.02)$, lower serum albumin $(\mathrm{p}=0.004)$, calcium $(\mathrm{p}=0.005)$, and a higher estimated glomerular filtration rate $(p=0.001)$ at baseline.

\section{Frequency and incidence of cancer death}

A total of 274 deaths were observed during the followup period, with $84(30.7 \%)$ and $124(45.3 \%)$ cancer and vascular deaths, respectively. Cancers of the digestive system $(27,32.1)$ were the most common cause of cancer death, followed by lung (13, 15.4\%), haematological (11, $13.0 \%)$, breast $(6,7.1 \%)$, and cancers of the central nervous system $(5,6.0 \%)$.

\section{Association between serum $25(\mathrm{OH}) \mathrm{D}$ concentrations and cancer-mortality}

Table 2 shows the unadjusted and adjusted risk factors for cancer mortality. A significant increase in cancer mortality was observed in those with reduced levels of serum $25(\mathrm{OH})$ D concentrations. Figure 1 shows how the adjusted hazard ratio (HR) for incident cancer death changes as the continuous measures of serum $25(\mathrm{OH})$ $\mathrm{D}$ concentrations move further away from the median value of $64 \mathrm{nmol} / \mathrm{L}$ (which has an HR of 1). For every $30 \mathrm{nmol} / \mathrm{L}$ reduction in serum $25(\mathrm{OH}) \mathrm{D}$ concentrations, there was a significant increase in cancer-specific mortality by $33 \%$ from a threshold of $64 \mathrm{nmol} / \mathrm{L}$, after adjusting for the effects of age, seasonal changes, chronic kidney disease and smoking status (adjusted HR: 1.33; 95\% confidence interval $(\mathrm{CI}): 1.03-1.72, \mathrm{p}=0.02)$. Compared to participants with serum $25(\mathrm{OH})$ D concentrations greater than or equal to $64 \mathrm{nmol} / \mathrm{L}$, the adjusted HR for cancer death among those with serum 25 $(\mathrm{OH}) \mathrm{D}$ concentrations less than $64 \mathrm{nmol} / \mathrm{L}$ was 1.61 (95\% CI: $1.02-2.54, \mathrm{p}=0.04$ ). We have also shown that the best-fit fractional polynomial was linear in the adjusted model (Additional file 1). 
Table 2 Risk factors for cancer mortality

\begin{tabular}{|c|c|c|c|c|c|c|}
\hline Variables & $\begin{array}{l}\text { Unadjusted } \\
\text { HR }\end{array}$ & $95 \% \mathrm{Cl}$ & P-values & Adjusted HR & $95 \% \mathrm{Cl}$ & p-values \\
\hline \multicolumn{7}{|l|}{ Patient characteristics } \\
\hline Age (per SD increase) & 1.05 & $0.86-1.28$ & 0.64 & 1.02 & $0.84-1.25$ & 0.83 \\
\hline Diastolic blood pressure (per 10 mmHg increase) & 1.10 & $0.90-1.34$ & 0.35 & - & - & - \\
\hline Systolic blood pressures (per 10 mmHg increase) & 0.97 & $0.87-1.09$ & 0.60 & - & - & - \\
\hline Previous and current smoker & 1.45 & $0.97-2.17$ & 0.07 & 1.80 & $1.17-2.77$ & 0.008 \\
\hline Body mass index (per SD increase) & 0.99 & $0.81-1.21$ & 0.93 & - & - & - \\
\hline Daily alcohol use (per gram increase) & 1.09 & $0.85-1.41$ & 0.49 & - & - & - \\
\hline \multicolumn{7}{|l|}{ Co-morbidities } \\
\hline Diabetes & 1.32 & $0.61-2.86$ & 0.48 & - & - & - \\
\hline Chronic kidney disease & 2.37 & $1.27-4.50$ & 0.007 & 2.43 & $1.28-4.62$ & 0.007 \\
\hline Cardiovascular disease & 1.30 & $0.74-2.27$ & 0.36 & - & - & - \\
\hline \multicolumn{7}{|l|}{ Season at recruitment } \\
\hline Spring & Ref & - & 0.39 & Ref & - & - \\
\hline Summer & 2.07 & $0.63-6.78$ & & 1.02 & $0.24-4.34$ & 0.97 \\
\hline Autumn & 1.48 & $0.87-2.54$ & & 1.71 & $0.99-3.00$ & 0.06 \\
\hline Winter & 1.17 & $0.70-1.96$ & & 1.27 & $0.75-2.14$ & 0.37 \\
\hline \multicolumn{7}{|l|}{ Treatment allocation } \\
\hline Calcium supplements & 1.11 & $0.76-1.63$ & 0.59 & 1.09 & $0.73-1.62$ & 0.67 \\
\hline \multicolumn{7}{|l|}{ Laboratory measurements } \\
\hline \multicolumn{7}{|l|}{$25(\mathrm{OH})$ Vit D (nmol/L) } \\
\hline$>83$ & Ref & - & 0.06 & Ref & - & 0.04 \\
\hline$>64-83$ & 1.95 & $1.02-3.74$ & & 2.23 & $1.09-4.58$ & \\
\hline$>46-64$ & 2.27 & $1.21-4.27$ & & 2.55 & $1.24-5.26$ & \\
\hline $0-46$ & 2.12 & $1.11-4.05$ & & 2.63 & $1.26-5.45$ & \\
\hline Albumin (per SD increase) & 0.95 & $0.79-1.13$ & 0.53 & - & - & - \\
\hline Calcium (per SD increase) & 1.01 & $0.83-1.22$ & 0.93 & - & - & - \\
\hline Phosphate (per SD increase) & 0.70 & $0.14-3.46$ & 0.66 & - & - & - \\
\hline Estimated GFR (per SD increase) & 1.03 & $0.84-1.27$ & 0.78 & - & - & - \\
\hline
\end{tabular}

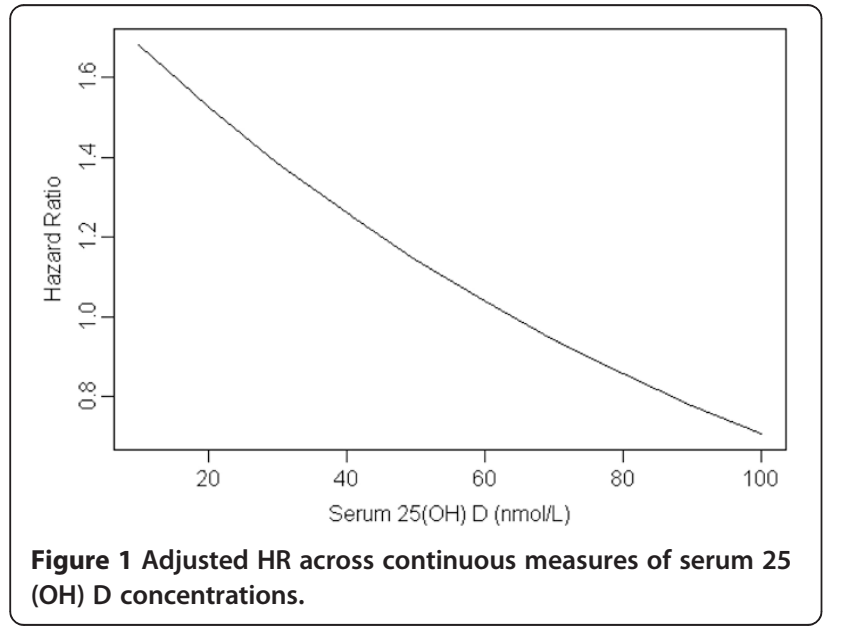

\section{Cumulative incidence probability after adjustment for competing risk of death}

Figure 2 shows the adjusted cumulative incidence of cancer mortality and the serum $25(\mathrm{OH})$ D concentrations (dichotomized below and/or above the group median value of $64 \mathrm{nmol} / \mathrm{L}$ ) after adjusting for competing vascular deaths, age, smoking status, systolic and diastolic blood pressures. The cumulative incidence of cancer mortality among participants with $25(\mathrm{OH})$ D concentrations $<64 \mathrm{nmol} / \mathrm{L}$ and $\geq 64 \mathrm{nmol} / \mathrm{L} 10$ years after inception of the study were 0.096 and 0.062 , respectively $(\mathrm{p}=0.02)$.

\section{Site-specific risk of cancer death}

Figure 3 shows the selected site-specific HR for cancer death for every $30 \mathrm{nmol} / \mathrm{L}$ increase in serum $25(\mathrm{OH}) \mathrm{D}$ concentrations. There was a significant association 


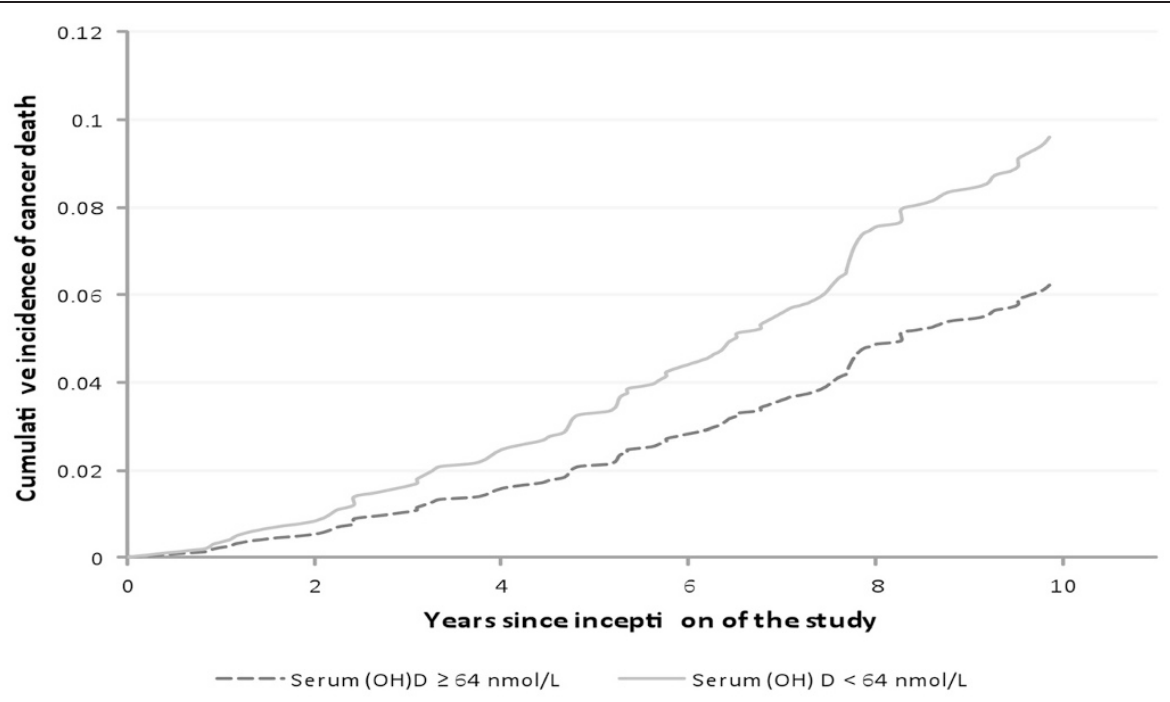

Number at risk

\begin{tabular}{|l|l|l|l|l|l|}
\hline Serum 25 (OH) D <64 nmol/L & 580 & 561 & 539 & 506 & 465 \\
\hline Serum 25 (OH) D $\geq 64 \mathrm{nmol} / \mathrm{L}$ & 590 & 578 & 559 & 531 & 489 \\
\hline
\end{tabular}

Figure 2 Adjusted cumulative incidence of cancer mortality by serum $25(\mathrm{OH}) \mathrm{D}$ concentrations.

between reduced serum $25(\mathrm{OH})$ D concentrations and increased risk of death from haematological cancers after adjusting for the effects of age, smoking status, seasonal changes and chronic kidney disease (adjusted HR: 2.13; 95\% CI: $1.0-4.55, \mathrm{p}=0.05)$. This association was not significant in other cancer types including digestive, lung, breast, female genital and cancers of the central nervous systems.

\section{Sensitivity analyses}

We also analyzed the cancer mortality risk comparing those with very low serum $25(\mathrm{OH})$ D concentrations (less than $46 \mathrm{nmol} / \mathrm{L}$ ) to those with baseline serum 25 $(\mathrm{OH}) \mathrm{D}$ concentrations $\geq 83 \mathrm{nmol} / \mathrm{L}$ and found an increased risk of cancer death by at least 2.6-fold among those with very low serum $25(\mathrm{OH}) \mathrm{D}$ concentrations (adjusted HR: 2.63; 95\%CI: $1.26-5.45, \mathrm{p}=0.04$ ). In

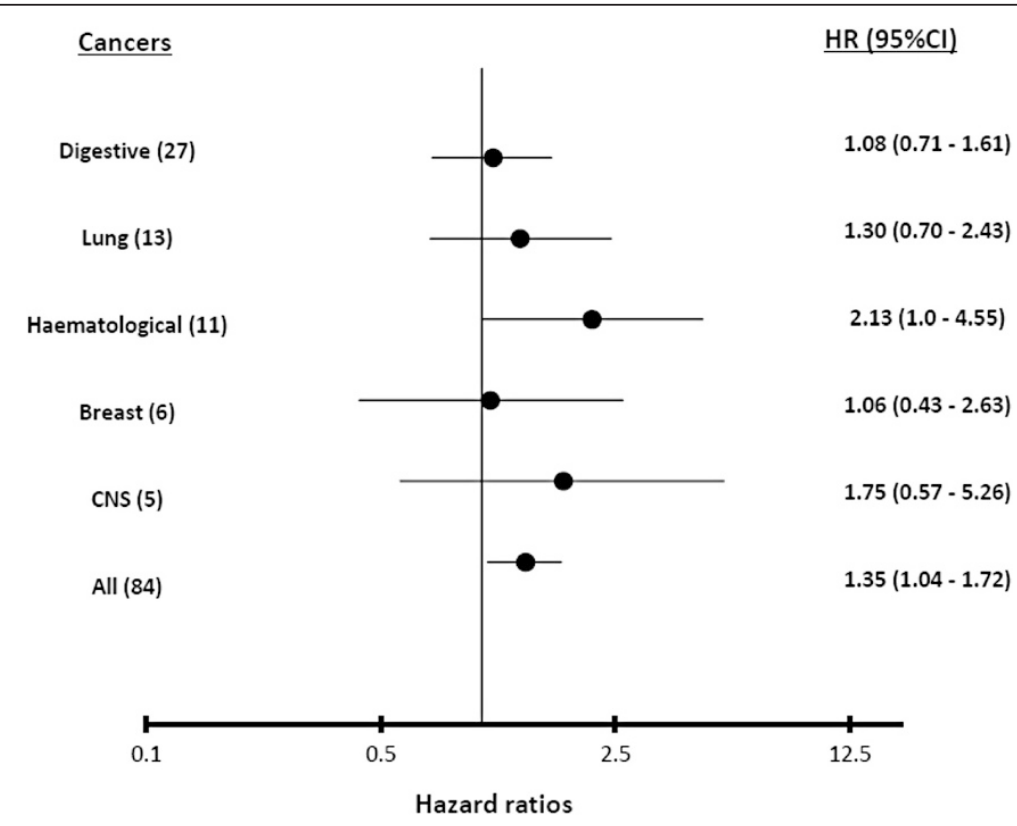

Figure 3 Serum $25(\mathrm{OH}) \mathrm{D}$ concentrations and site-specific cancer mortality. 
addition, the risk of overall cancer death among those with serum $25(\mathrm{OH}) \mathrm{D}$ concentration below the median (less than $64 \mathrm{nmol} / \mathrm{L}$ ) remained significant after excluding participants who died from cancer within the first two years since inception of the study (adjusted HR: 1.59; $95 \%$ CI: $1.03-2.44, \mathrm{p}=0.04$ ).

\section{Association between serum $25(\mathrm{OH}) \mathrm{D}$ concentrations and cancer incidence}

A total of 191 incident cancers were observed during the follow-up period. The cumulative incidence of cancer among participants with serum $25(\mathrm{OH})$ D concentrations $<64 \mathrm{nmol} / \mathrm{L}$ and $\geq 64 \mathrm{nmol} / \mathrm{L}$ ten years after inception of the study were 0.19 and 0.18 , respectively $(\mathrm{p}=0.60)$ (Figure 4). After adjusting for measured confounders, cancer risk was not significantly increased among those with serum $25(\mathrm{OH})$ D concentrations below the median value (adjusted HR: 0.89, 95\%CI: 0.67 - 1.18, $\mathrm{p}=0.41$, for those with $25(\mathrm{OH}) \mathrm{D}$ levels less than $64 \mathrm{nmol} / \mathrm{L}$ ).

\section{Discussion}

In this large study of Australian women, with over 12,000 person-years of follow-up, we have shown that women with lower baseline were at an increased risk of overall cancer death but not for incident cancer. For every $30 \mathrm{nmol} / \mathrm{L}$ reduction in serum $25(\mathrm{OH}) \mathrm{D}$ concentrations, there was an increased risk of cancer specific mortality by at least 30\%, after adjusting for the effects of age, seasonal changes, smoking status and chronic kidney disease. The increased risk of cancer death also appeared to be sitespecific, with the greatest risk of death from haematological malignancies observed among women with lower serum $25(\mathrm{OH}) \mathrm{D}$ concentrations.

To our knowledge, this is a large population-based cohort study with the longest follow-up time to date investigating the association between serum $25(\mathrm{OH}) \mathrm{D}$ concentrations and the overall and site-specific risk of cancer mortality in

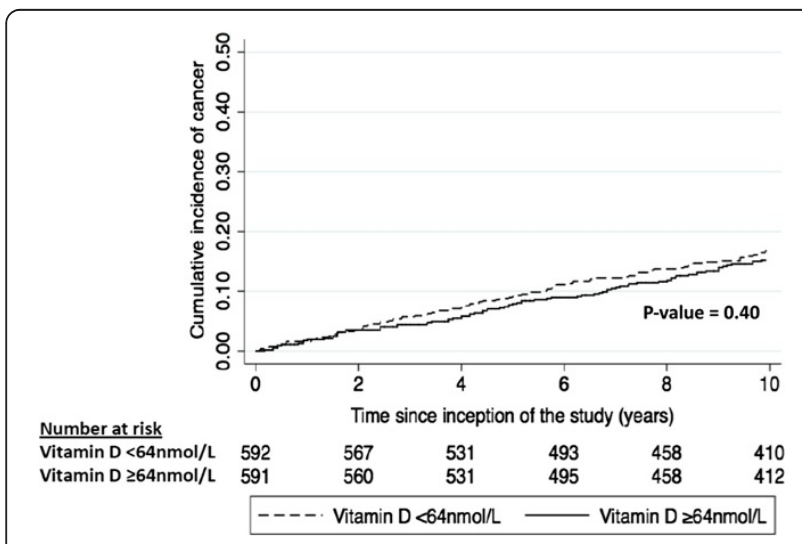

Figure 4 Cumulative incidence of cancer by serum $25(\mathrm{OH})$ D concentrations. elderly women. Low serum $25(\mathrm{OH}) \mathrm{D}$ concentrations have been shown to be associated with adverse clinical outcomes among those suffering from cancers. Previous ecological studies have reported breast cancer mortality was highest for cancer diagnosed in winter, the seasons with the highest serum $25(\mathrm{OH})$ D concentrations [21]. Lower serum 25 $(\mathrm{OH}) \mathrm{D}$ concentrations have also been associated with more advanced stages of breast cancers. More recently, a prospective cohort study of over 1300 older women suffering from breast cancer has shown that lower serum $25(\mathrm{OH}) \mathrm{D}$ concentrations were linearly associated with 10\% increased risk of cancer-related mortality and a $15 \%$ increased risk of disease recurrence for every $10 \mathrm{nmol} / \mathrm{L}$ decrement in serum 25 $(\mathrm{OH}) \mathrm{D}$ concentrations [22].

Previous studies that have investigated the association between cancer mortality and serum $25(\mathrm{OH})$ D concentrations have observed conflicting results. Several population-based cohort studies have reported an association between higher serum $25(\mathrm{OH}) \mathrm{D}$ concentrations and reduction in overall cancer mortality $[15,23,24]$. In particular, significant inverse associations were observed for colorectal, pancreatic, oral and esophageal cancer mortality $[12,25]$. In contrast, results from the National Health and Nutrition Examination Survey (NHANES) study of over 16,000 participants, have shown no significant associations between serum $25(\mathrm{OH})$ D concentrations and overall cancer mortality after adjustments for age, gender, smoking and ethnicity [16].

A significant association between haematological malignancies was detected among those with reduced serum $25(\mathrm{OH})$ D concentrations. Although the exact biological rationale for the protective effects of vitamin $\mathrm{D}$ is unclear, findings from animal studies have shown that vitamin D can stimulate the production of a known antagonist of c-myc, a protein critical in promoting cell proliferation and the transformation of pre-malignant to malignant cells [26]. In addition, in vitro studies have also shown that the active metabolite of Vitamin D, 1,25 $(\mathrm{OH}) 2 \mathrm{D}$, can inhibit the proliferation, angiogenesis and metastatic potential of tumour cells thereby suggesting a critical role of vitamin D in the control of cancer cell growth [27]. Studies have also reported a poorer prognosis among those with hypovitaminosis D in a cohort of patients with chronic lymphocytic leukaemia. The overall hazard for death is at least 1.6 times greater among patients with serum $25(\mathrm{OH})$ D concentrations less than $25 \mathrm{ng} / \mathrm{ml}$. In vitro studies have shown that treatment with Vitamin D analogues induces apoptosis of the mitochondrial pathway, therefore leading to inhibition of the proliferation of the B and $\mathrm{T}$ lymphocytes and lymphoma cell lines.

The higher serum $25(\mathrm{OH})$ D concentration thresholds that predicted the increased risk of cancer mortality in our study cohort is unexpected. Most published literature 
described a cut-off point of $50 \mathrm{nmol} / \mathrm{L}$ and its association with the increased risk of overall and site-specific cancer death [28]. The higher than predicted threshold for the increased risk of cancer mortality may be due to chance or potential measurement errors such as regression dilution errors. Random measurement error in the exposure variable may potentially attenuate the association between vitamin $\mathrm{D}$ concentrations and cancer mortality at the pre-specified thresholds. This occurs because the measurements often fluctuate unpredictably around the true values, due to biological variations or imprecision of the measurement tool itself. The exposure factor, serum $25(\mathrm{OH}) \mathrm{D}$ concentrations in our study, were measured only once at baseline, rather than repeatedly to minimize the potential errors. Our findings suggest future trials may consider higher doses of vitamin $\mathrm{D}$ to achieve a target serum $25(\mathrm{OH}) \mathrm{D}$ concentration of $60 \mathrm{nmol} / \mathrm{L}$ or greater when evaluating the benefits and harms of vitamin D supplementation in older women with cancers.

Our study has a number of strengths. It is populationbased, with very little missing baseline data, and over 12 , 647 person years of follow up. Detailed data on confounders were also available. Using linked data from a mandatory state-wide cancer registry, we have accurately ascertained all cancer deaths since inception of the cohort.

Our study has a number of potential limitations. We excluded $17.1 \%$ of the original sample because of incomplete serum $25(\mathrm{OH})$ vitamin D concentrations, but the number is relatively small, and those excluded have similar characteristics to those in the overall study population. The progressive change in serum $25(\mathrm{OH}) \mathrm{D}$ concentrations over time and the risk of cancer death was not evaluated because only baseline serum $25(\mathrm{OH})$ $\mathrm{D}$ concentrations were available. Findings from our study may not be generalisable to other populations such as the African Americans and Indigenous Australians because all participants are white post-menopausal Australian women. The lack of association between site-specific cancer mortality and serum $25(\mathrm{OH})$ D concentrations may be due to the limited number of events for individual site-specific cancers, and therefore insufficient power to detect any significant differences in the risk of cancer deaths among women with lower and higher serum $25(\mathrm{OH})$ D concentrations. Finally, although we had fully adjusted for all known risk factors for cancer death available in the dataset, residual confounding by other unmeasured socioeconomic and epidemiological factors such as physical activity and ultraviolet exposure may be present.

\section{Conclusions}

In conclusion, lower baseline serum $25(\mathrm{OH}) \mathrm{D}$ concentrations were independently associated with an increased risk of overall cancer mortality. However, the threshold of serum $25(\mathrm{OH})$ D concentrations associated with the increased risk of cancer mortality may vary according to the characteristics of the study population. Additional prospective studies are required to investigate the association between serum $25(\mathrm{OH})$ D concentrations and site-specific and overall incidence and mortality in older populations of both genders. Future carefully designed randomised controlled trials of vitamin D supplementation in older adults with cancers may be warranted to determine whether this association is causal and potentially reversible.

\section{Ethics approval}

The Human Ethics Committee of the University of Western Australia approved the study and written informed consents were obtained from all participants. Approval number: 05/06/004/H50.

\section{Additional file}

Additional file 1: Fractional polynomial model assessing the linearity assumption between serum $25(\mathrm{OH})$ D concentrations and cancer mortality.

\section{Abbreviations}

$25(\mathrm{OH})$ D: 25-hydroxy-vitamin D; CAIFOS: Calcium Intake Fracture Outcome Study; CV: Coefficients of variation; WADLS: Western Australia Data Linkage System; ICD: International Classification of Diseases; IQR: Interquartile range; HR: Hazard ratio; NHANES: National Health and Nutrition Examination Survey.

\section{Competing interests}

The authors declare that they have no competing interests.

\section{Authors' contributions}

GW proposed the study and drafted the manuscript. WL, JL, JC, RT, ZK, EL and $\mathrm{RP}$ reviewed the preliminary analyses and initial draft of the manuscript and provided critical comments. All authors have seen the final submitted manuscript and agree with its contents. The statistical analyses were carried by GW, RT and WL. GW is the guarantor, has full access to all of the data in the study, and takes responsibility for the integrity of the data and the accuracy of the data analysis. GW and WL conceived the study, participated in its design and coordination and drafting of the manuscript. GW performed the statistical analyses. All authors revised the drafts, read and approved the final manuscript.

\section{Acknowledgements}

The study was supported by Kidney Health Australia grant S07 10, Healthway Health Promotion Foundation of Western Australia and by project grants 254627, 303169 and 572604 from the National Health and Medical Research Council of Australia. The salary of Joshua Lewis is supported by a Raine Medical Research Foundation Priming Grant. Robin Turner is supported by a NHMRC program grant (no. 633003) to the Screening \& Test Evaluation Program. No other authors declare a conflict of interest.

\section{Author details}

${ }^{1}$ Centre for Kidney Research, Children's Hospital at Westmead, Westmead, Australia. ${ }^{2}$ School of Public Health, Sydney Medical School, The University of Sydney, Sydney, Australia. ${ }^{3}$ Centre for Transplant and Renal Research, Westmead Hospital Westmead, Westmead, Australia. ${ }^{4}$ University of Western Australia School of Medicine and Pharmacology, Sir Charles Gairdner Hospital Unit, Perth, Australia. ${ }^{5}$ Department of Renal Medicine, Sir Charles Gairdner Hospital, Perth, Australia. ${ }^{6}$ Department of Endocrinology and Diabetes, Sir 
Charles Gairdner Hospital, Perth, Australia. ${ }^{7}$ PathWest, Sir Charles Gairdner Hospital, Perth, Australia.

Received: 24 March 2014 Accepted: 21 February 2015 Published online: 08 March 2015

\section{References}

1. Arnson Y, Gringauz I, Itzhaky D, Amital H. Vitamin D deficiency is associated with poor outcomes and increased mortality in severely ill patients. QJM. 2012;105(7):633-9.

2. Fan C, Nieto FJ, Bautista LE, Fine JP. Vitamin D intake and cardiovascular mortality in the NHANES I epidemiological follow-up study cohort. J Dietary Supplements. 2012;9(2):79-89.

3. Eaton CB, Young A, Allison MA, Robinson J, Martin LW, Kuller LH, et al. Prospective association of vitamin $\mathrm{D}$ concentrations with mortality in postmenopausal women: results from the women's health initiative $(\mathrm{WHI})$. Am J Clin Nutr. 2011;94(6):1471-8.

4. Formiga F, Ferrer A. Low Serum Vitamin D is Not Associated with an Increase in Mortality in Oldest Old Subjects: The Octabaix Three-Year Follow-Up Study. Gerontology. 2014;60(1):10-5.

5. Cui Y, Rohan TE. Vitamin D, calcium, and breast cancer risk: a review. [Review] [105 refs]. Cancer Epidemiol Biomark Prev. 2006;15(8):1427-37.

6. Mizoue T, Kimura Y, Toyomura K, Nagano J, Kono S, Mibu R, et al. Calcium, dairy foods, vitamin D, and colorectal cancer risk: the Fukuoka colorectal cancer study. Cancer Epidemiol Biomark Prev. 2008;17(10):2800-7.

7. Robien K, Cutler GJ, Lazovich D. Vitamin D intake and breast cancer risk in postmenopausal women: the lowa women's health study. Cancer Causes Control. 2007;18(7):775-82.

8. Yin L, Grandi N, Raum E, Haug U, Arndt V, Brenner H. Meta-analysis: circulating vitamin D and ovarian cancer risk. [review]. Gynecol Oncol. 2011;121(2):369-75.

9. Yin L, Grandi N, Raum E, Haug U, Arndt V, Brenner H. Meta-analysis: longitudinal studies of serum vitamin D and colorectal cancer risk. Aliment Pharmacol Ther. 2009;30(2):113-25.

10. LaCroix AZ, Kotchen J, Anderson G, Brzyski R, Cauley JA, Cummings SR, et al. Calcium plus vitamin D supplementation and mortality in postmenopausal women: the women's health initiative calcium-vitamin D randomized controlled trial. J Gerontol Series A-Biol Sci Med Sci. 2009;64(5):559-67.

11. Lappe JM, Travers-Gustafson D, Davies KM, Recker RR, Heaney RP. Vitamin D and calcium supplementation reduces cancer risk: results of a randomized trial. Am J Clin Nutr. 2007;85(6):1586-91. Erratum appears in Am J Clin Nutr. 2008 Mar;87 (3):794

12. Giovannucci E, Liu Y, Willett WC. Cancer incidence and mortality and vitamin D in black and white male health professionals. Cancer Epidemiol Biomark Prev. 2006;15(12):2467-72.

13. Giovannucci E, Liu Y, Rimm EB, Hollis BW, Fuchs CS, Stampfer MJ, et al. Prospective study of predictors of vitamin D status and cancer incidence and mortality in men. J Natl Cancer Inst. 2006;98(7):451-9.

14. Freedman D, Fuhrman B, Graubard BI, Chang SC. Vitamin D and cancer mortality. Cancer Epidemiol Biomark Prev. 2009;18(1):359-60.

15. Schottker B, Haug U, Schomburg L, Kohrle J, Perna L, Muller H, et al. Strong associations of 25 -hydroxyvitamin $D$ concentrations with all-cause, cardiovascular, cancer, and respiratory disease mortality in a large cohort study. Am J Clin Nutr. 2013;97(4):782-93.

16. Freedman DM, Looker AC, Abnet CC, Linet MS, Graubard BI. Serum 25-hydroxyvitamin D and cancer mortality in the NHANES III study (1988-2006). Cancer Res. 2010;70(21):8587-97.

17. Tomson J, Emberson J, Hill M, Gordon A, Armitage J, Shipley M, et al. Vitamin D and risk of death from vascular and non-vascular causes in the Whitehall study and meta-analyses of 12000 deaths. Eur Heart J. 2013;34(18):1365-74.

18. Lazzeroni M, Serrano D, Pilz S, Gandini S. Vitamin D supplementation and cancer: review of randomized controlled trials. [review]. Current Med Chem Anti-Cancer Agents. 2013;13(1):118-25.

19. Lewis JR, Calver J, Zhu K, Flicker L, Prince RL. Calcium supplementation and the risks of atherosclerotic vascular disease in older women: results of a 5-year RCT and a 4.5-year follow-up. J Bone Mineral Res. 2011;26(1):35-41.

20. Fine JP, Gray RJ. A proportional hazards model for the subdistribution of a competing risk. J Am Stat Assoc. 1999;94:496-509.

21. Lim HS, Roychoudhuri R, Peto J, Schwartz G, Baade P, Moller H. Cancer survival is dependent on season of diagnosis and sunlight exposure. Int J Cancer. 2006;119(7):1530-6.
22. Vrieling A, Hein R, Abbas S, Schneeweiss A, Flesch-Janys D, Chang-Claude J. Serum 25-hydroxyvitamin D and postmenopausal breast cancer survival: a prospective patient cohort study. Breast Cancer Res. 2011;13(4):R74.

23. Michaelsson K, Baron JA, Snellman G, Gedeborg R, Byberg L, Sundstrom J, et al. Plasma vitamin D and mortality in older men: a community-based prospective cohort study. Am J Clin Nutr. 2010;92(4):841-8.

24. Pilz S, Tomaschitz A, Obermayer-Pietsch B, Dobnig H, Pieber TR. Epidemiology of vitamin D insufficiency and cancer mortality. [Review] [33 refs]. Anticancer Res. 2009;29(9):3699-704.

25. Ren C, Qiu MZ, Wang DS, Luo HY, Zhang DS, Wang ZQ, et al. Prognostic effects of 25-hydroxyvitamin D levels in gastric cancer. J Transl Med. 2012;10:16.

26. Salehi-Tabar R, Nguyen-Yamamoto L, Tavera-Mendoza LE, Quail T, Dimitrov $\mathrm{V}$, An BS, et al. Vitamin D receptor as a master regulator of the c-MYC/ MXD1 network. Proc Natl Acad Sci U S A. 2012;109(46):18827-32.

27. Zheng W, Wong KE, Zhang Z, Dougherty U, Mustafi R, Kong J, et al. Inactivation of the vitamin D receptor in APC (min/+) mice reveals a critical role for the vitamin $\mathrm{D}$ receptor in intestinal tumor growth. Int J Cancer. 2012;130(1):10-9.

28. Zittermann A, lodice S, Pilz S, Grant WB, Bagnardi V, Gandini S. Vitamin D deficiency and mortality risk in the general population: a meta-analysis of prospective cohort studies. Am J Clin Nutr. 2012;95(1):91-100.

\section{Submit your next manuscript to BioMed Central and take full advantage of:}

- Convenient online submission

- Thorough peer review

- No space constraints or color figure charges

- Immediate publication on acceptance

- Inclusion in PubMed, CAS, Scopus and Google Scholar

- Research which is freely available for redistribution 